5. Heit.

(Abgeschlossen am 16. April 1953.)

WoLL, E., Einwirkung von Nucleinsäuren und ihren Baustoffen auf die Wurzelspitzenmitose. Mit 34 Textabbildungen . . . . . . . . . . . 391

LINNERT, G., Der Einfluß von Chemikalien auf Chiasmenbildung und Mutationsauslösung bei Oenothera . . . . . . . . . . . . . . . . . . . . . . 428

LIPP, Сн., Über Kernwachstum, Endomitosen und Funktionszyklen in den trichogenen Zellen von Corixa punctata ILLJG. Mit 25 Textabbildungen . 454

INouk, S., Polarization optical studies of the mitotic spindle. I. The demonstration of spindle fibers in living cells. With 15 figures in the text . . . 487

Konze, E., Untersuchungen über die Paarungsaffinität bei Riesenchromosomen. Mit 3 Textabbildungen . . . . . . . . . . . . 501

\title{
6./7. Hett.
}

(Abgeschlossen am 21. August 1953.)

Mechelke, F., Reversible Strukturmodifikationen der Speicheldrüsenchromosomen von Acricotopus lucidus. Mit 31 Textabbildungen . . . . . . . . 511

Hughes-Schrader, S., The nuclear content of desoxyribonucleic acid and interspecific relationships in the mantid genus Lituryousn (Orthoptera: Mantoidea). With 2 figures in the text . . . . . . . . . . . . . 544

Smitr, S. G., A pseudo-multiple sex-chromosome mechanism in an indian gryllid. With 33 figures in the text . . . . . . . . . . . . . . . 555

Tschermak-Woess, E., und G. Hastrschka. Veränderungen der Kernstruktur während der Fndomitose, rhythmisches Kernwachstum und verschiedenes Heterochromatin bei Angiespermen. Vit 19 Textabbildungen. . . . . . 574

Antorenverzeichnis des ri Bandes . . . . . . . . . . 615

Register für die Bände... . . . . . . . . . 616

\section{ERRATA}

Hoft 8, 8. 805 Der auf den Zeilen 18 und 17 von unten stehende Passus „Epidermiszellen auf. Ebenso ist auch der Kern größor als die übrigen" gehört zwischen die Wörter „übrigen" und "Epidermis." auf Zeile 16 von unten. Der richtige Text der Zeilen 18 bis 16 von unten lautet:

„verzweigte Haare. Die Haarinitiale fällt durch ihre Größe gegenüber den übrigen Epidermiazellen auf. Ebenso ist auch der Kern größer als die übrigen Epidermis.".

Heit 4, S. 375 Fig. 1. The caption should be changed to read: "Fig. $1 \mathrm{~A}$ and B. a Gilia millefoliata ..., c G. achilleaefolia ..., and $\mathrm{b}$ their allotetraploid..." 